\title{
Seasonal Changes Effecting theGrowth Performance of Emu Birds Reared under Intensive Farming System
}

\author{
B. Saivinay ${ }^{1}$, CH. Harika ${ }^{1}$, B. R. Naik ${ }^{1 *}$, A. V. N. Siva Kumar ${ }^{1}$, \\ L. S. S. Vara Prasad Reddy ${ }^{1}$ and B. Hari Mallikarjuna Reddy ${ }^{2}$
}

${ }^{1}$ Department of Physiology, College of Veterinary Science, Sri Venkateswara Veterinary

University, Tirupati - 517502, Andhra Pradesh, India

${ }^{2}$ Department of Statistics, Sri Venkateswara University, Tirupati - 517502,

Andhra Pradesh, India

*Corresponding author

\section{A B S T R A C T}

\begin{tabular}{|l|}
\hline K e y w or d s \\
Emu chicks, \\
Growers, Finishers, \\
Average daily body \\
weight gain
\end{tabular}

Growth performance of emu birds was evaluated with respect to season to assess the bird's average daily weight gain from starter to slaughter weight maintained under intensive farming system. Study was done on a total flock size of 1000(n) birds at a commercial farm near Tirupati, Andhra Pradesh for 57 weeks closely associated different seasonal conditions. Emus are reared under in open sided within fenced areas in the tropical countries, any variation in the climatic conditions would greatly impact on their production. The results indicated that the emus showed higher average live body weight gain at growing stage and performed significantly better in winter with respect to summer season due to increased appetite and feed intake during low temperatures were observed. It was concluded that the anatomical and physiological adaptation of emus was desirable during low temperatures and emus of 15-27 weeks of agegrown in low temperatures showed higher growth performance.

\section{Introduction}

Emu (Dromaius novaehollandiae) belongs to the order of ratites with its flightlessness and large size as characteristic features. Intensive farming concentrates getting more output with using high input strategies. Emu farming has been a booming business in India due to its fast growth and maturity, along with enormous advantage of red meat which is $98 \%$ fat free, emu oil is having oleic acid with antiaging and anti-inflammatory properties, skin and feathers which are of high economic value and egg is considered to be a good nutritive product and are also demanded for its aesthetics (Suganya et al., 2017). Emu flocks are more vulnerable to climatic changes because birds can only tolerate narrow temperature ranges which affect their growth rates (Rajashekher Reddy et al., 2018).

They are considered to be desirable for farming under Indian conditions due to their physiological and anatomical adaptation to temperate and tropical regions (Warale et al., 2014). The growth rate is affected by 
nutrition, season and water intake (Buclaw et al., 2017). The cost of weight gain is an important determinant of the total cost of production, the growth process described for emus could be a valuable strategy to selectively breed emu chicks to grow rapidly over a short period with high gain-to-feed ratios and maturing rates (Goonewardene et al., 2003). The aim of this paper is to study the growth performance of emus based on feeding, watering and analyzed activities were compared with seasons that is summer (March to August) and winter (September to February).

\section{Materials and Methods}

Commercial emu farm located near Tirupati, Andhra Pradesh was selected (latitude $13 \circ 36 ' 59.5$ 'N and longitude $79 \circ 18^{\prime} 47.7{ }^{\prime} \mathrm{E}$ ). During the entire period of the observations made in the emu farm located at Tirupati, the analyzed flock was maintained under intensive system of rearing.

The new flock was introduced into the farm with a total of 1000(n) birds, and were selected for the study and observed for the growth performance for the respective periods From October, 2016 To December, 2017.

Proper care was taken regarding the starter birds(0-14weeks, Fig1) by maintaining them under the shed and incubators, remaining growers(15-34 weeks, Fig 2) and finishers (35-57 weeks, Fig 3) were reared in open sided within a fenced area. All the birds were grouped according to different ages with 3 weeks interval $(0-3,3-6,6-9,9-12,12-15,15-$ 18, 18-21, 21-24, 24-27, 27-30, 30-33, 33-36, $36-39$, 39-42, 42-45, 45-48, 48-52, 52-57).

The feeding was done twice a day, in the morning and evening at constant rate regardless of season and water was provided ad libitum (Table 1).

\section{Average Daily Weight Gain}

The average daily weight gain of starters and growers of different age groups were calculated for summer and winter seasons using the following formula (Suganya et al., 2017).

$G=\frac{\mathrm{w}_{2}-\mathrm{w}_{1}}{\mathrm{t}_{2}-\mathrm{t}_{1}}$

$\mathrm{G}=$ average daily weight gain (in grams)

$\mathrm{w}_{2}-\mathrm{w}_{1}=$ weight gain during a period

$t_{2}-t_{1}=$ period in days

The amount of feed provide to the emu birds were $0.2 \mathrm{~kg}$ feed per bird per day until 1014 weeks of age (until they attain $10 \mathrm{~kg}$ body weight) and $1 \mathrm{~kg}$ of feed per bird per day from 15-57 weeks of age and water is provided ad libitum.

The averages temperatures recorded in different seasons during study period were

October 2016- February 2017- winter season (0-18 weeks of age) $-28{ }^{\circ} \mathrm{C}$

March 2017- August 2017 - summer season $(18-42$ weeks of age $)-32.83{ }^{\circ} \mathrm{C}$

September 2017- December 2017- winter season $(42-57$ weeks of age $)-27.84^{\circ} \mathrm{C}$

Average live body weight gain of emus at 3 weeks intervals from $0-57$ weeks shown in TABLE 2.

\section{Results and Discussion}

\section{Seasonal Effects}

Average body weight gain was affected by the seasons. 
Fig.1 Starters (0-14Weeks)

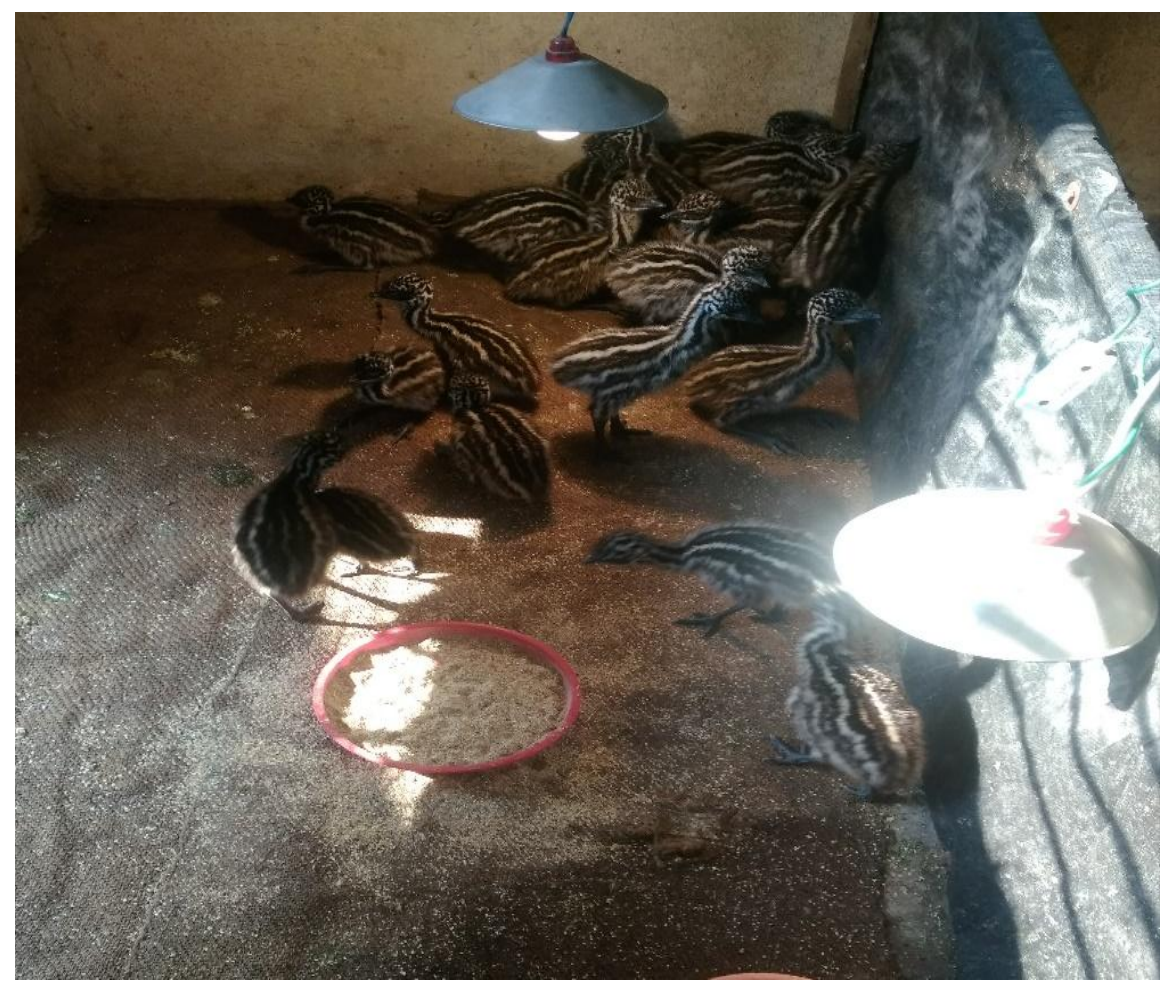

Fig.2 Growers (15-34 Weeks)

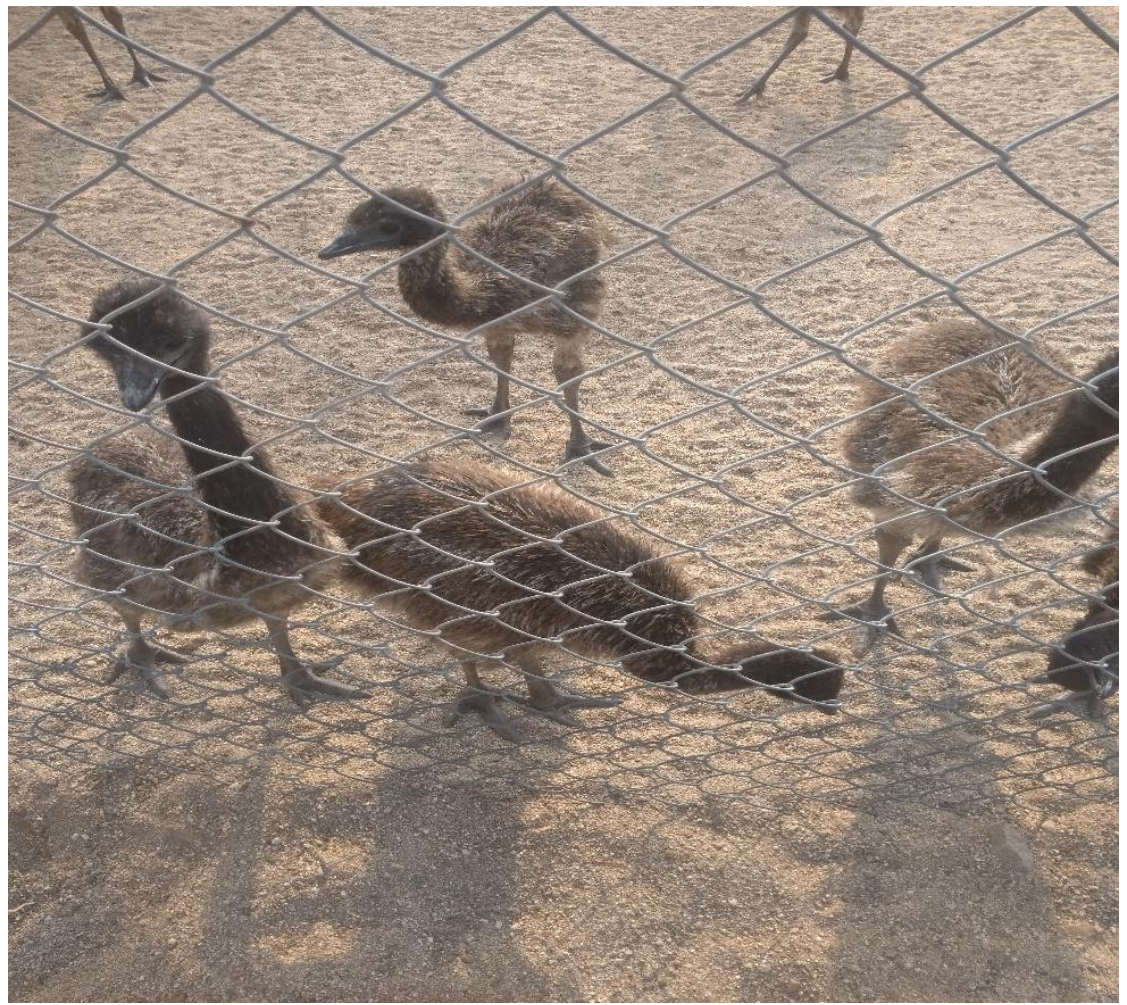


Fig.3 Finishers (35-57 Weeks)

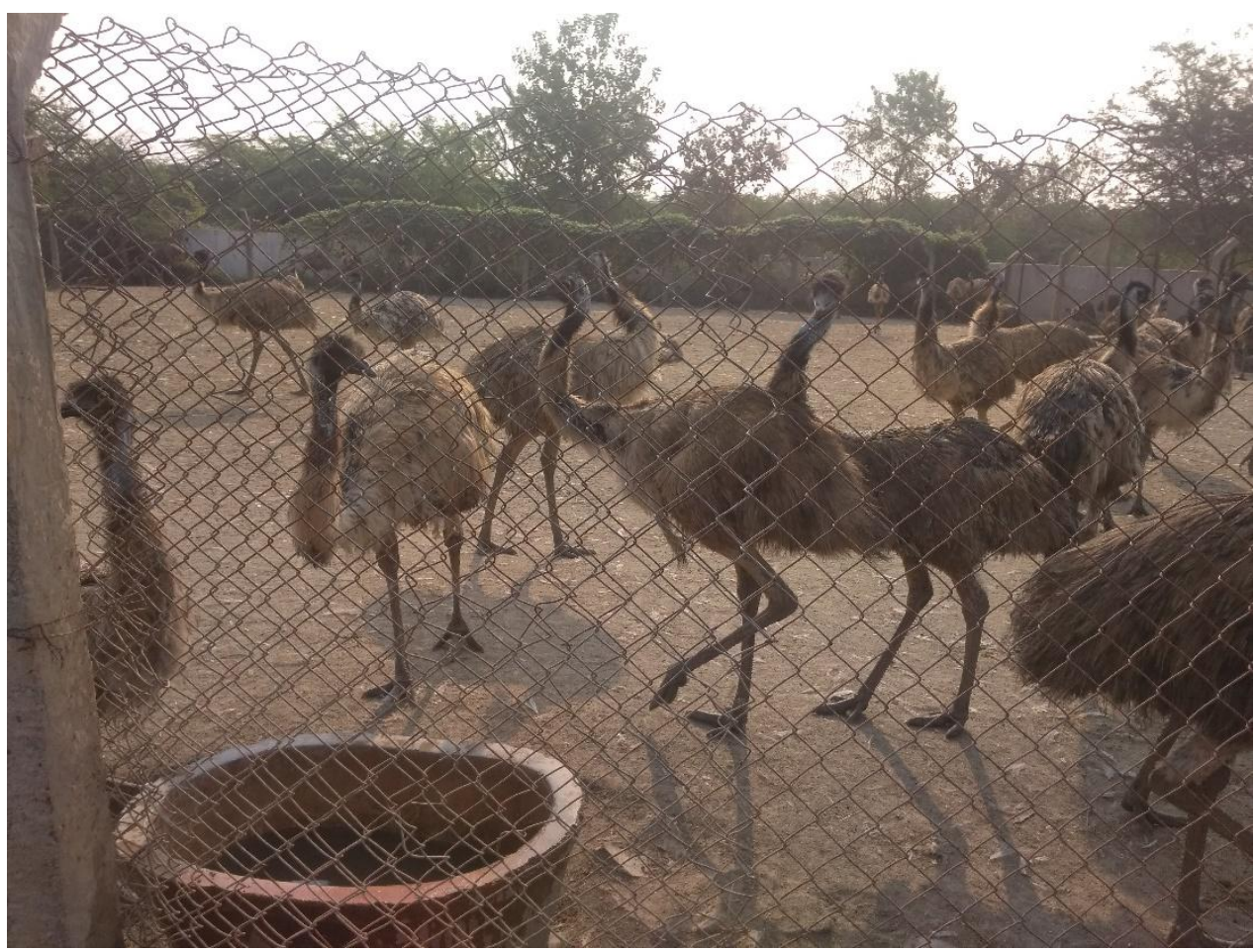

Fig.4 Growth Performance of Emu Birds

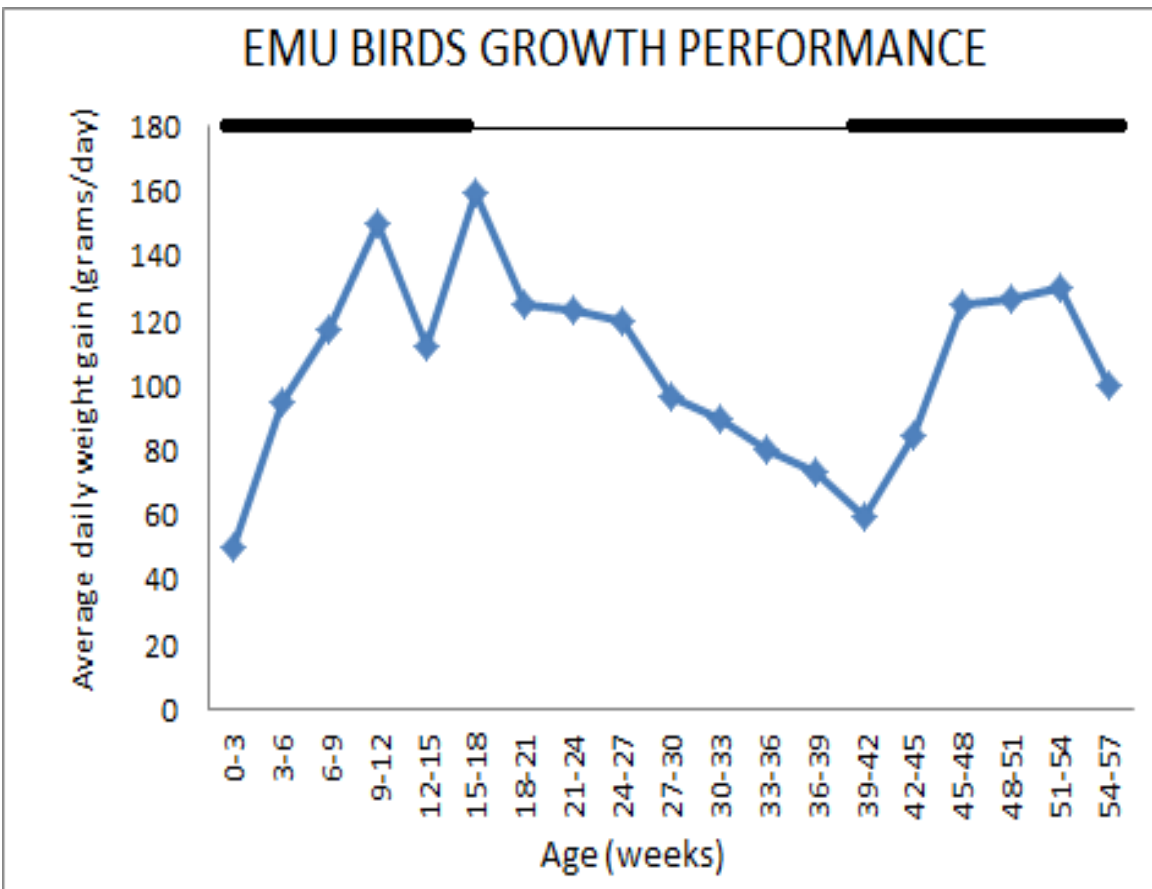

Indicates winter season

Indicates summer season 
Table.1 Emu Feed consists of Kg/100kg (Rao N S, 2004)

\begin{tabular}{|l|l|l|l|}
\hline Parameter & Starter(0-14 weeks) & $\begin{array}{l}\text { Grower (15-34 weeks } \\
\text { age) }\end{array}$ & $\begin{array}{l}\text { Finisher (35-57weeks } \\
\text { age) }\end{array}$ \\
\hline Maize & 50 & 45 & 60 \\
\hline Soyabean meal & 30 & 25 & 20 \\
\hline DORB & 10 & 16.25 & 16.25 \\
\hline Sunflower & 6.5 & 10 & 0 \\
\hline Dicalcium phosphate & 1.5 & 1.5 & 1.5 \\
\hline Calcite powder & 1.5 & 1.5 & 1.5 \\
\hline Vitamins & 0.1 & 0.1 & 0.1 \\
\hline Salt & 0.3 & 0.3 & 0.3 \\
\hline Trace minerals & 0.1 & 0.1 & 0.1 \\
\hline Methionine & 0.25 & 0.15 & 0.25 \\
\hline Choline chloride & 0.05 & 0.05 & 0.05 \\
\hline Water & Ad libitum & Ad libitum & Ad libitum
\end{tabular}

Table.2 Average Daily Weight Gain of Emu Birds in Different Seasons

\begin{tabular}{|c|c|c|c|c|c|}
\hline \multicolumn{2}{|c|}{ Winter 2016-2017 } & \multicolumn{2}{|c|}{ Summer 2017} & \multicolumn{2}{|c|}{ Winter 2017} \\
\hline Age & $\begin{array}{l}\text { Average daily } \\
\text { weight gain (grams) }\end{array}$ & Age & $\begin{array}{l}\text { Average daily } \\
\text { weight gain (grams) }\end{array}$ & Age & $\begin{array}{l}\text { Average daily } \\
\text { weight gain (grams) }\end{array}$ \\
\hline $0-3$ & 50 & $18-21$ & 125 & $42-45$ & 85 \\
\hline 3-6 & 95 & $21-24$ & 123 & $45-48$ & 125 \\
\hline $6-9$ & 117 & $24-27$ & 120 & $48-51$ & 127 \\
\hline $9-12$ & 150 & $27-30$ & 97 & $51-54$ & 130 \\
\hline $12-15$ & 112 & $30-33$ & 90 & $54-57$ & 100 \\
\hline $15-18$ & 160 & $33-36$ & 80 & & \\
\hline & & $36-39$ & 73 & & \\
\hline & & $39-42$ & 60 & & \\
\hline
\end{tabular}

Appetite and growth showed a gradual decline due to reduced feed intake from May, 2017 to July, 2017 (during peak temperatures) at the age of 15-27weeks and increase in appetite led to replacement of growth reserves from September, 2017 to December, 2017 (during low temperatures) at the age of $42-57$ weeks as per farm climatic conditions (Fig 4).

The present study on the growth performance of the emu birds maintained under intensive farming conditions of India helps in documentation that the emus of age 15-27 weeks of age reared under low temperatures/winter season attain higher daily weight gain, and they have a low feed cost per unit weight gain which would be economically feasible and flourishes the emu farming industry for meat, leather and oil necessarily primary to cover the cost of feed.

\section{References}

Bucław. M \& Szczerbińska. D (2017) Seasonal and daily changes in the behavior of the adult emu (Dromaius 
novaehollandiae) under farm http://www.poulvet.com/poultry/articles conditions. Online journal http://www.tandfonline.com and article link

http://dx.doi.org/10.1080/00071668.201 7.1340587,3-8

Goonewardene. L.A., Wang. Z, Okine. E, Zuidhof. M.J, Dunk. E, and Onderka. D (2003) Comparative Growth Characteristics of Emus (Dromaius novaehollandiae), Published in $\angle 2003$ Poultry Science Association, Inc, 30

Malley. P O, (1995) Nutrition of Ratites: Comparison of Emu and Ostrich Requirements, Recent Advances in Animal Nutrition in Australia: July 1995 University of New England, Armidale NSW 2351, Australia, 53-57

Rajashekher Reddy (2018) Poultry Experimental Station, Livestock Research Institute Acharya N.G. Ranga Agricultural University, Hyderabad: Commercial Emu and Ostrich rearing,

Rao N S (2004). A study on the performance of emu (Dromaius novaehollandiae) in Andhra Pradesh. MVSc thesis submitted to the Acharya N.G. Ranga Agricultural University, Hyderabad

Suganya G, Leela. V, Paramasivam. A and Richard Jagatheesan. P (2017) Growth performance of emu chicks reared under intensive farming conditions, International Journal of Science, Environment and Technology, Vol. 6, No 6, 3367 - 3371

Warale RH, Chauhan HD, Dilip Parmar, Kulkarni RC, Srivastava AK, Makwana RB, Pawar MM and Bhagwat SR (2014), Emu Farming: An Alternative to Indian Poultry, Trends in Veterinary and Animal Sciences | Year-2014 | Volume 1 | Pages 09-14 (C) 2014 Jakraya Publications (P) Ltd.

\section{How to cite this article:}

Saivinay B., CH. Harika, B. R. Naik, A. V. N. Siva Kumar, L. S. S. Vara Prasad Reddy and Hari Mallikarjuna Reddy B. 2018. Seasonal Changes Effecting theGrowth Performance of Emu Birds Reared under Intensive Farming System. Int.J.Curr.Microbiol.App.Sci. 7(06): 17801785. doi: https://doi.org/10.20546/ijcmas.2018.706.211 